\title{
International Classification of Diseases, Tenth Revision
}

National Cancer Institute

\section{Source}

National Cancer Institute. International Classification of Diseases, Tenth Revision. NCI

Thesaurus. Code C71892.

The tenth version of the International Classification of Diseases (ICD), published by the World Health Organization in 1992. 